\title{
NeOLIBERALISMO, INSERCIÓN INTERNACIONAL Y FINANCIARIZACIÓN: UNA COMPARACIÓN ENTRE Argentina y Portugal
}

\begin{abstract}
Andrés Musacchio ${ }^{a}$
Fecha de recepción: 25 de julio de 2019. Fecha de aceptación: 5 de diciembre de 2019. http://doi.org/10.22201/iiec.20078951e.2020.201.69442

Resumen. El presente trabajo intenta analizar el neoliberalismo periférico financiarizado (NPF) como forma específica del neoliberalismo. Tras presentar cuatro formas diferentes y criterios para delimitarlas, se estudian las características generales del NPF. Se destacan una matriz común de políticas, un modelado similar de estructuras productivas centradas en la acumulación financiera y una articulación común a los procesos de valorización internacionales. Comparando dos países que ejemplifican el NPF (Argentina y Portugal), se corrobora la caracterización general. Pero también se observan especificidades en la regulación monetaria, la inserción internacional y los mecanismos de la regulación poblacional, que le dan al modelo cadencias específicas, importantes para analizar las crisis y las alternativas para estructurar políticas de desarrollo diferentes.
\end{abstract}

Palabras clave: neoliberalismo financiarizado periférico; economía financiarizada; sector financiero; política monetaria y cambiaria; grado de autonomía.

Clasificación JEL: G15; O11; P34; P52.

\section{NEOLIBERALISM, INTERNATIONAL INSERTION AND FINANCIALIZATION: a COMParison between Argentina and Portugal}

\begin{abstract}
This paper aims to analyze financialized peripheral neoliberalism (FPN) as a specific form of neoliberalism. After presenting four different forms FPN can take and criteria to delimit them, its general characteristics are examined. The paper highlights a common policy matrix, a similar model of production structures focused on financial accumulation, and a common formulation of international valorization processes. Comparing two countries that exemplify FPN (Argentina and Portugal), the above general characterization is corroborated. However, specificities in monetary regulation, international insertion and population regulation mechanisms are also observed, which give the model specific nuances important for analyzing crises and proposing alternatives for differently structured development policies.
\end{abstract}

Key Words: financialized peripheral neoliberalism; financialized economy; financial sector; monetary and exchange rate policy; degree of autonomy.

\footnotetext{
${ }^{a}$ Universidad de Buenos Aires/CONicET. Correo electrónico: andresmusacchio@hotmail.com
} 


\section{INTRODUCCIÓN}

Este trabajo se propone explorar comparativamente algunas características de los modelos económicos que en las últimas décadas han predominado en $\mathrm{Ar}$ gentina y Portugal. Pero, ¿qué hace a ambas experiencias comparables? Intuitivamente, al escuchar a Amalia Rodrigues cantarle a Lisboa, se intuyen esos paraguas de Buenos Aires de Amelita Baltar. La razón propone razones que la ciencia no admite. Hay, entonces, otras cuestiones más compatibles con el rigor académico que tornan una comparación de interés al respecto. Incluso más allá de las propuestas inspiradas en la coyuntura portuguesa que, al momento de escribir este artículo, se presentan en Argentina como un posible camino de salida a la crisis.

En primer lugar, con desfases temporales, existen trayectorias económicas recientes con similitudes llamativas que dan pie a una comparación. La evolución de algunas variables, pero sobre todo, el desarrollo de la matriz productiva y algunos determinantes de dichos desarrollos tienen rasgos comunes. En última instancia, se trata entonces de modelos del mismo tipo. Es lo que se sostendrá en la primera parte de este trabajo: Argentina y Portugal son claros ejemplos de una misma variante del neoliberalismo.

Por eso, comparten algunas problemáticas en materia de desarrollo y de desequilibrios macroeconómicos, lo que genera desafíos compartidos. Si eso es así, la reflexión comparativa puede resultar fructífera para pensar alternativas económicas y políticas que permitan superar los desafíos del desarrollo de largo plazo. Mucho más cuando los desfases temporales en los ciclos dan pie para evaluar potenciales senderos y problemas.

Así como el fado y el tango expresan sentimientos parecidos, tienen una notoria identidad propia; lo mismo ocurre con las economías y sociedades argentina y portuguesa. Siendo modelos de la misma matriz, tienen diferencias destacables que, no obstante, permiten un potencial explorativo adicional. Cabe preguntarse, por ejemplo, qué tan profunda es la influencia de dos imbricaciones externas diferentes. O hasta dónde dos regímenes cambiaros de similar concepción teórica, pero técnicamente distintos, inciden en trayectorias distintas. $\mathrm{O}$, por caso, cuál es la influencia de dos formas de regulación distintas de la población. Sin la pretensión de agotar aquí el tema o cerrar debates, se plantean algunas hipótesis para responder a dichos cuestionamientos.

En las páginas siguientes (sección 2), se abordarán las diferentes variantes, las diversas formas que admite el neoliberalismo, tratando de situar en ese esquema estructurado el lugar que les cabe a Argentina y Portugal. Se ubicarán a ambos dentro de la variante denominada "neomercantilismo periférico finan- 
ciarizado", que se analizará con algo de detalle en la tercera sección, misma en la que se tratará de mostrar por qué Argentina y Portugal tienen una matriz común. Establecida esa base general, en la cuarta sección se tocarán las diferencias marcadas que ambos países muestran incluso adscribiendo a la misma variante. Las crisis en las que regularmente cae la financiación periférica permitirá, finalmente, enhebrar algunas reflexiones basadas en las salidas que, en contextos especiales, ambos países han intentado transitar y que podrían constituirse en puntos de apoyo para un cambio de modelo.

\section{EL NEOLIBERALISMO Y SUS FORMAS}

En trabajos anteriores, Musacchio (2018, 2019a) destaca la gran variabilidad que admite el neoliberalismo. Si bien el modelo genérico puede caracterizarse a partir de un conjunto de elementos básicos (Musacchio, 2013) -como un manto común que lo distingue de otros modelos-, algunas singularidades permiten identificar tipologías específicas definidas por la combinación de dos planos diferentes. Uno se apoya en la morfología de la estructura productiva $\mathrm{y}$, en especial, en las relaciones y proporciones entre los sectores de bienes y de servicios, con un énfasis especial del sector financiero. El segundo plano considera el grado de autonomía interna de cada país para definir el modulado local de la estructura productiva. A continuación se verán estas dos cuestiones a detalle.

\section{"Neomercantilismo" vs. acumulación impulsada por las finanzas}

La morfología de la estructura productiva determina dos grandes variantes dentro del neoliberalismo. Lapavitsas (2013, p. 201) apunta con razón que el primer elemento para calibrar la importancia relativa del sector financiero es distinguir entre acumulación real y acumulación financiera. El neoliberalismo resulta -en una perspectiva abstracta- de una combinación de transformaciones en el proceso de organización de la producción y de la intensificación de la valorización financiera. Combina, por tanto, ambas formas de acumulación. Analizado desde una perspectiva concreta y asociada a los espacios nacionales, una de las formas predomina sobre la otra y lidera el proceso de acumulación. Esto no significa que la otra forma desaparezca; incluso puede tomar un vuelo cuantitativo importante. Sin embargo, cualitativamente se subordina a, o de- 
pende de, la otra forma. Así, se puede distinguir entre una variante impulsada por la producción y otra por las finanzas.

En la primera, que se denominará neomercantilismo, el modelado de la estructura productiva tiene como actor dinámico principal al sector productor de bienes, sobre todo, al sector industrial. Allí se gesta el núcleo del proceso de valorización del capital. En el marco de una libre movilidad de capitales -típica del neoliberalismo- que estimula la competencia entre las locaciones físicas de los procesos productivos, se corporiza una fuerte presión para reducir costos, que suele estimular la reducción en los impuestos al capital o a la riqueza, así como una distribución crecientemente regresiva del ingreso. La baja de tasas impositivas genera un impacto fiscal negativo, que suele compensarse reduciendo el gasto público, especialmente en seguridad social. Así, el fortalecimiento de la producción es acompañado por una contracción del mercado interno que obliga a una salida exportadora. Aunque en realidad, se inicia un círculo vicioso entre la distribución regresiva y la presión competitiva, que va agudizando la situación.

De esta manera, producción y exportaciones se entrelazan cada vez más y, como el mercado interno se comprime, las importaciones no mantienen un ritmo equilibrado de crecimiento, dando paso a crecientes superávit comerciales. De allí la denominación de neomercantilismo. Dado que el avance de las exportaciones se conjuga con una reducción del mercado interno, el modelo deja poco margen para el crecimiento y la inversión, dando lugar a la paradoja de fuertes ganancias y baja inversión. La acumulación de recursos se vuelca al mercado financiero, de modo que la financiarización es consecuencia de las características del aparato productivo (Huffschmid, 2008, p. 60).

En otros casos, el núcleo dinámico principal se sitúa en el sector financiero. El rol central de las finanzas es el que determina en lo esencial qué sectores crecen o se bloquean. La producción se estructura de manera "residual", acoplada a la dinámica financiera, que dicta el pulso del proceso de valorización. En general, el devenir se encadena en torno a burbujas especulativas en títulos o en el mercado inmobiliario, mientras los procesos de endeudamiento público y privado forman parte estructural del proceso. Los altos rendimientos financieros de corto plazo limitan el espacio productivo a actividades con tasas de ganancia extraordinarias (las únicas capaces de competir con la burbuja en el auge) y suelen ser acompañadas de un proceso inflacionario comparativamente alto.

Dado que en el neoliberalismo la norma es la apertura comercial, la alta inflación deviene de una revalorización de los servicios que aprecia la moneda local, quita competitividad a la producción de bienes (cuyos precios son 
determinados por los precios internacionales) e infla las ganancias en moneda extranjera. En general, entonces, el "neoliberalismo financiarizado" permite un crecimiento espasmódico impulsado por servicios, construcción y recursos naturales. Y ya que los inversores son reacios a comprometer recursos de largo plazo (Bortz y Kaltenbrunner, 2019), pequeñas modificaciones en la coyuntura o en las estrategias de los actores tienen impactos significativos, provocando una gran volatilidad.

El sector financiero tiene un papel superlativo en ambas formas, pues la acumulación financiera aparece hipertrofiada. En tanto, en el neoliberalismo financiarizado comanda el proceso, en el neomercantilismo es sólo el resultado de las debilidades de la estrategia productiva, aunque el sector productivo comanda el proceso.

\section{La cuestión de la autonomía relativa}

El segundo aspecto que determina las formas que adopta el neoliberalismo es el grado de autonomía de los países. Aunque los procesos internos siempre reciben la influencia del contexto internacional, de los actores externos, de las estrategias de los competidores o de las oportunidades, desafíos y bloqueos que genera una división particular del trabajo, el grado de autonomía es muy diferente de un país al otro. ¿Dónde se toman las principales decisiones de política económica? ¿Quién determina la estructura de los precios relativos? ¿Quién controla y orienta el movimiento espacial y la utilización del excedente económico?

La historia muestra (y el neoliberalismo no es una excepción) que algunas naciones tienen un grado de autonomía claramente mayor que otras y proyectan, incluso, su influencia sobre los organismos internacionales. Estas, a su vez, gestan con sus políticas una ampliación en la brecha de autonomía. ${ }^{1}$

El grado de autonomía no es resultado de una distribución arbitraria del poder, sino que se asocia a las diferencias en el grado de desarrollo de las fuerzas productivas y de las estructuras del mismo. El control sobre los medios tecnológicos, financieros y legales ${ }^{2}$ que juegan un rol central en cada etapa del capitalismo es tan decisivo como los medios de "persuasión" y violencia.

\footnotetext{
La literatura sobre esto es tan extensa como sus debates. $C f$. Van der Pijl (2006, 2014).

¿Quién determina la legalidad internacional? El análisis de la construcción de las instituciones como el FMI o la OMC muestra el rol rector de las grandes potencias, cuya influencia en la formación del orden económico global o regional se acrecienta notablemente. Para el caso del FMI, $c f$. Block (1977).
} 
Algunos países dominan los tramos esenciales de las cadenas productivas y el proceso de creación tecnológica en los sectores clave para una etapa determinada y proyectan, a partir de ello, una influencia determinante en el modelado de la estructura productiva, mientras otros resultan modelados o deben encontrar su espacio en una división del trabajo que se les impone ( $c f$. Mistral, 1986; Beaud, 1987).

Así, por el grado de autonomía, el neoliberalismo recrea y amplía la división entre países desarrollados y subdesarrollados, temática que bajo la reedición de categorías como centro-periferia o dependencia-independencia viene siendo revalorizada recientemente, no siempre con una precisión adecuada. ${ }^{3}$ Independiente de la denominación, un rasgo característico de los países subdesarrollados es la aparición o intensificación de los mecanismos de transferencias de recursos: por la vía de los servicios de la deuda, las remisiones de utilidades, la fuga de capitales -especialmente por parte de las élites locales-, la privatización/extranjerización de la propiedad colectiva (sobre todo en el segmento inmaterial de la propiedad intelectual), la absorción de costos ambientales, o en la migración calificada, además de los fenómenos tradicionales como el "intercambio desigual" (Musacchio, 2018; Marcó del Pont y Todesca, 2019).

Esta característica, resultado de la radicalización de la apertura comercial y la liberalización financiera en un mundo de gran movilidad del capital, es uno de los puntos de apoyo principales en la concentración espacial del ingreso (complementaria a la concentración funcional). El intento de establecer acuerdos de libre comercio, que dificulten la reversión de la apertura, la liberalización financiera o la amplitud máxima de los derechos de propiedad, resulta una pieza clave del juego.

El neoliberalismo refuerza, entonces, las transferencias internacionales de recursos - con algunas formas novedosas y reforzando las tradicionales-; mientras la normativa y las relaciones de poder que se despliegan tienen como resultado la imposición de estándares aceptados en los diseños de políticas nacionales que no surgen de una discusión democrática sino de la imposición. A su vez, tanto las normativas como algunas macropolíticas (como los regímenes de tipo de cambio fijo) limitan drásticamente los instrumentos para la ejecución de políticas. Tanto el establecimiento de esos estándares como el atenerse a utilizarlos o no, son ejemplos de diferencias notables de autonomía de las que gozan algunos países desarrollados frente a los subdesarrollados. 
$\mathrm{Al}$ igual que en modelos anteriores, buena parte de los instrumentos y de las políticas no aceptables son aquellos que tienen mayor incidencia en posibles transformaciones de las estructuras productivas y, por lo tanto, pueden poner en cuestionamiento a partir de un desarrollo de las fuerzas productivas la relación entre ambos polos. Es decir, se inhibe la utilización de los instrumentos para preservar el statu quo y, por lo tanto, en las autonomías relativas.

Las diferencias de autonomía se observan con claridad cuando, por caso, se toma el problema de la deuda. Como destaca Wolf (2015, p. 177) al comparar los senderos del ajuste en EUA y Europa. A nivel global, el principal deudor (EUA) es mucho más poderoso y, por ende, tiene mayor autonomía que los acreedores (China especialmente). En la Eurozona, en cambio, el acreedor principal, Alemania, es más poderoso que los deudores y puede imponer un ajuste deflacionario al resto. Y concluye "la diferencia es simple: Alemania controla el banco central relevante; China no". El mismo fenómeno puede ser enfrentado de maneras diferentes, de acuerdo al margen de maniobra que tienen las políticas internas.

\section{La conjunción de ambas problemáticas y las cuatro formas del neoliberalismo}

Si se combinan los dos criterios expuestos (la relación finanzas-producción y las diferencias de autonomía) se conforman cuatro formas principales: a) neomercantilismo "central" (por ejemplo, Alemania, Holanda); $b$ ) neoliberalismo financiarizado "central" (por ejemplo, Gran Bretaña); c) neomercantilismo "periférico" (por ejemplo, República Checa); y d) neoliberalismo "periférico" financiarizado (por ejemplo, Argentina, Portugal) (véase cuadro 1).

Como suele ocurrir con cualquier esquematización, las formas rara vez se presentan puras o sin contradicciones. Sin embargo, en cada país suele predominar de manera clara en largos periodos alguna de las cuatro formas.

Dichas formas no pueden desplegarse fuera de un entramado de relaciones internacionales. De tal manera que, si un país mantiene un abultado saldo comercial favorable, por ejemplo, deben existir contrapartes, socios comerciales con déficit comerciales en espejo. Estos, a su vez, se financian con una deuda que necesita de acreedores que posean un capital financiero prestable. En realidad, el vínculo es mucho más profundo que una mera cuestión de saldos de transacciones corrientes e involucra un entramado más complejo de relaciones internacionales y de normativas de las que puede profundizarse sobre la articulación entre desarrollo y subdesarrollo. Por eso, dicha temática, 
ausente durante mucho tiempo en la discusión, vuelve a cobrar relevancia con trabajos como el de Álvarez et al. (2013); Musacchio (2019b) o Coimbra (2017); no se abordará este tema ni sus ciclos, analizados a grandes rasgos en Musacchio $(2018,2019$ a), pues no es el objetivo. Sin embargo, debe tenerse presente para comprender lo que a continuación se explicará sobre Argentina y Portugal, dos ejemplos del (NFP).

Cuadro 1. Formas del neoliberalismo

\begin{tabular}{|c|c|c|c|}
\hline \multirow{3}{*}{$\begin{array}{l}\text { - Estructura productiva } \\
\text { articuladora. } \\
\text { - Modelado interno de la EP. } \\
\text { - Receptor neto de riqueza. } \\
\text { - Determinante de las } \\
\text { políticas "permitidas". }\end{array}$} & \multicolumn{2}{|c|}{$\begin{array}{l}\text { - Producción modela la estructura productiva (EP). } \\
\text { - Acumulación financiera "residual". } \\
\text { - Economía industrial exportadora. }\end{array}$} & \\
\hline & $\begin{array}{l}\text { Neomercantilismo } \\
\text { "central" }\end{array}$ & $\begin{array}{l}\text { Neomercantilismo } \\
\text { "periférico" }\end{array}$ & \multirow{2}{*}{$\begin{array}{l}\text { - Estructura productiva } \\
\text { incompleta y desarticulada } \\
\text { - Modelado externo de la EP. } \\
\text { - Fuga sistemática de } \\
\text { riqueza. } \\
\text { - Restricción externa sobre } \\
\text { las políticas "permitidas". }\end{array}$} \\
\hline & $\begin{array}{l}\text { Neoliberalismo } \\
\text { financiarizado } \\
\text { "central" }\end{array}$ & $\begin{array}{l}\text { Neoliberalismo } \\
\text { financiarizado } \\
\text { "periférico" }\end{array}$ & \\
\hline & \multicolumn{2}{|c|}{$\begin{array}{l}\text { - Finanzas modelan la EP. } \\
\text { - Producción determinada de manera "residual". } \\
\text { - Crecimiento impulsado por servicios y recursos } \\
\text { naturales. }\end{array}$} & \\
\hline
\end{tabular}

Fuente: elaboración propia.

\section{BREVE CARACTERIZACIÓN DEL NPF Y PRIMEROS ELEMENTOS PARA UNA COMPARACIÓN}

El NPF es, pues, una forma en la que el proceso económico se encuentra modelado por el sector financiero y con un grado de autonomía nacional ostensiblemente limitado. En general, se asocia a estructuras productivas incompletas, con muchos vacíos sobre todo en el sector industrial, que reflejan una desarticulación interna del sistema productivo. Tanto la falta de eslabones vitales de la cadena como la desarticulación tienen raíces históricas profundas, ${ }^{4}$ que coronan una debilidad estructural y una fuerte dependencia de decisiones que

4 Para Argentina, un análisis de las raíces históricas del problema puede consultarse en Rapoport et al. (2000) y la literatura allí indicada. Para Portugal, cf. Reis (2018). 
se toman en el exterior a los espacios nacionales. Tales rasgos se profundizan en el momento de incorporarse pasivamente al proceso de financiarización.

No se trata, por cierto, de un modelo monótono, sino de un proceso que reconoce un ciclo con dos fases marcadas: expansión y crisis. La etapa expansiva no siempre enhebra un crecimiento definido e, incluso cuando este se produce, no todas las variables acompańan pues, por ejemplo, el empleo no siempre crece, incluso, a veces se reduce a pesar del crecimiento. Los desequilibrios que se generan en la etapa expansiva, suelen derivar a mediano o largo plazo en una crisis que suele asumir la forma de un colapso en el balance de pagos.

En Argentina se distinguen tres momentos encuadrados en el NPF: 19771983; 1991-2001 y 2015 a la actualidad. El primero tuvo un corto auge, seguido desde 1980 por una prolongada crisis. El segundo, de un auge más largo y mayor volatilidad, pero con una crisis más profunda. Mientras que en el tercero el auge fue casi imperceptible. Portugal, por su parte, muestra dos procesos que se suceden; el primero abarca de 1993 a 2002 (con un auge moderado hasta 1998 y una posterior desaceleración) y el segundo entre 2003 y 2015. Allí es difícil hablar de una etapa expansiva, debido a la gran volatilidad del crecimiento ( $c f$. Reis, 2018, pp. 89-90).

\section{La fase expansiva}

La adopción del modelo suele iniciarse con un conjunto de políticas y de acuerdos que gestan las condiciones para su despliegue. La manera en la que se conciben esos procesos, las formas concretas de los programas y en las que se refleja la permeabilidad frente a las demandas externas queda, por supuesto, en la esfera de los espacios nacionales. En ellos se toman las decisiones de políticas que articulan a la élite política, a una parte de la élite económica y a una porción de la sociedad civil en el apoyo del programa. Sin embargo, adaptan también algunos intereses internos a las presiones externas que materializan los intereses de los países desarrollados, de los organismos internacionales y de actores externos privados. El proceso suele no carecer de contradicciones y, así como involucra a una parte de la élite económica, suele dejar fuera a otra porción. ${ }^{5}$ La cuestión es relevante, pues anula la hipótesis de que se trata de

5 Para Argentina, la confrontación entre sectores asociados al modelo financiero, a un modelo neomercantilista o a uno asociado al mercado interno fue tematizado frecuentemente. Cf. Azpiazu y Schorr (2010). 
un proceso inexorable o natural y remite a constelaciones de fuerzas internas y proyectos de nación importantes a la hora de diseñar alternativas.

Tanto en Argentina como en Portugal, la articulación entre grupos internos volcados a la valorización financiera, actores económicos externos y la decisiva participación de instituciones internacionales en la "persuasión" y en el diseño de los programas es clara. En Argentina, el asesoramiento del FMI es permanente y, en el programa de 1991, el ingreso al Plan Brady de renegociación de la deuda externa resulta un condicionante directo (Bazza et al., 2018, p. 137; Brenta, 2019, p. 133). En él se cristaliza la adopción del ancla cambiaria, la liberalización financiera y la apertura comercial, así como el esquema de privatizaciones y la ofensiva en la flexibilización laboral. La articulación entre los sectores internos y las "buenas prácticas" aceptadas internacionalmente queda más clara en la nueva fase que se abre en 2015, cuando la influencia del FMI es mucho menos decisiva y el programa se instala mucho menos coercitivamente, impulsado por una fracción interna de la élite, encabezada por los grupos financieros internos.

En Portugal, la incorporación a la Comunidad Económica Europea (CEE) es un reflejo tardío del acuerdo con el FMI de 1984, pero cristaliza también un giro drástico en la estrategia de las élites económicas (Léonard, 2016, p. 199). La incorporación a la CEE primero, luego al Tratado de Maastricht y por último a la Eurozona implicaron la adopción de un conjunto de normativas externas que impone un ajuste muy fuerte a los instrumentos de política económica y autonomía.

En general, el disparador es un plan de estabilización en el que se procura un disciplinamiento interno a partir de un vínculo más estrecho con la economía internacional o con la articulación a una región. ${ }^{6}$ El programa incluye la implementación o profundización de la apertura comercial y de la liberalización financiera, junto con una regla monetaria que fije el tipo de cambio nominal, vincule la moneda local a una moneda externa o, directamente, reemplace la moneda local por una externa. La lógica de ese "tríptico maldito" (apertura, liberalización y ancla cambiaria) es someter a la economía interna a la competencia del exterior, procurando que así se iguale la inflación interna a la internacional. El esquema, sin embargo, minimiza el rol de los precios de los bienes y los servicios no transables, no sometidos al proceso disciplinador y no condicionados por el sendero de precios previsto. Por lo tanto, la convergencia inmediata de las tasas de inflación es sólo una posibilidad hipotética.

6 Esto supone economías con un proceso inflacionario de una intensidad superior al promedio. 
Una rápida mirada a casos como el de Argentina, Portugal, Uruguay, España o Grecia indica que la inercia inflacionaria se prolonga luego de lanzado el plan. Las causas deben analizarse caso por caso, pero dos características resultan comunes: en primer lugar, aumentan los precios no disciplinados por el "tríptico maldito", los no transables. Eso significa que con la inflación se modifica la estructura de precios relativos, con un encarecimiento de los bienes no transables y determina una apreciación cambiaria, de revalorización real de la moneda local (o equivalente a, en caso de haberse adoptado una moneda externa). En segundo lugar, aunque el fenómeno de apreciación puede deberse a múltiples factores, por lo general, está relacionado con las medidas estructurales que suelen acompañar al "tríptico", como los ajustes fiscales para reducir el déficit, afectando a las tarifas de los servicios públicos, o la adecuación tarifaria con el fin de privatizar empresas del Estado. También la apertura al ingreso de empresas privadas en campos hasta entonces dominados por monopolios públicos tiene un efecto sobre los precios al segmentar el mercado. El éxito en las finanzas y en la construcción son elementos también presentes.

Bajo ese contexto, juega un rol central la forma del "ancla cambiaria", pues aunque en todas las experiencias el sector financiero se posiciona en el centro del proceso de acumulación, la forma de la regulación monetaria determina las características de la burbuja especulativa. No es lo mismo un régimen de metas cambiarias a futuro (Argentina 1978-1981), que un régimen de convertibilidad con $100 \%$ de cobertura con reservas de divisas del dinero (Argentina 1991-2001), un tipo de cambio flotante con flotación sucia (Argentina 2015 en adelante); la fijación de reglas de expansión monetaria, inflación, tasas de interés y devaluación referenciadas en un promedio regional (Portugal 19931999) o la adopción de una moneda común a la región de pertenencia (Portugal en la Eurozona), como se verá más adelante.

La contracara de la revaluación es, como se ha dicho, una alteración de la estructura de precios relativos que mella la competitividad de los bienes transables, por una triple vía: interna frente a los transables importados, en los mercados de exportación y frente a la rentabilidad del sector financiero, cuyas ganancias infladas actúan como un limitante de la inversión productiva. A largo plazo se desencadena una destrucción parcial del aparato productivo en el sector transable, especialmente en el sector industrial y en parte del sector agropecuario y pesquero. Sólo aquellos sectores con ganancias extraordinarias pueden sostener su posición. El impacto sobre el empleo suele ser notoriamente negativo. Tanto Argentina como Portugal son ejemplos claros de tal dirección (véase gráfica 1). 
Gráfica 1. Participación del sector agropecuario y la industria (en \% del PIB)

Argentina, 1974-1984

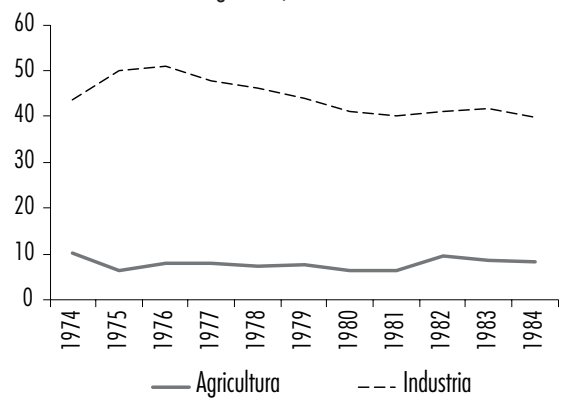

Argentina, 2014-2017

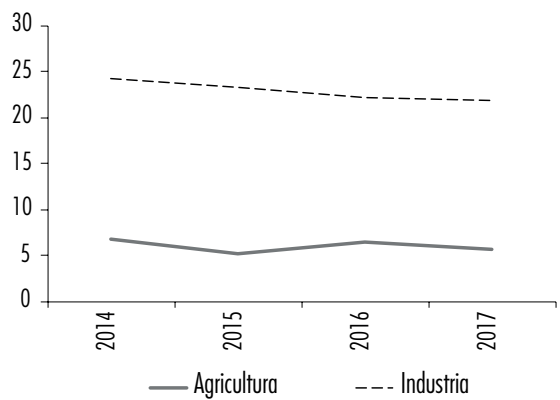

Argentina, 1990-2002

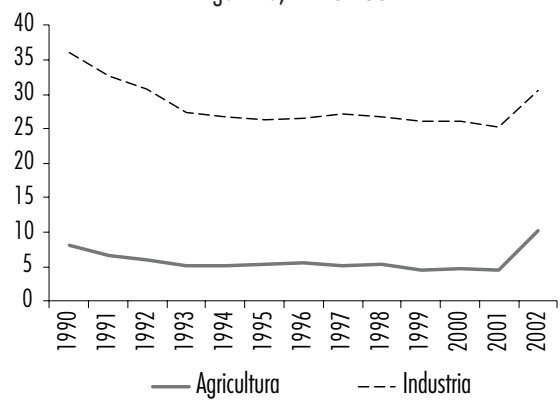

Portugal, 1995-2017

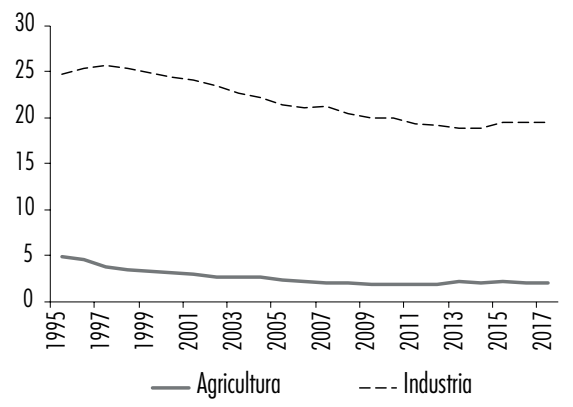

Fuente: elaboración propia con datos del Banco Mundial (<https://databank.worldbank.org/source/world-developmentindicators $>$ ).

El sector financiero condiciona entonces desde tres ángulos el desarrollo de la estructura productiva: el primero, la liberalización financiera, en especial la libre movilidad del capital, pone en competencia y desventaja a las locaciones productivas internas con las del exterior. El segundo, la rentabilidad inflada del sector financiero deja fuera de juego a sectores productivos con ganancias "normales" que, sin embargo, son inferiores a las de las actividades especulativas. Y por último, el volumen de crédito se destina a actividades con altas ganancias en el corto plazo, sin consideraciones sobre la sustentabilidad de largo plazo.

Otra característica, asociada al bajo nivel de acumulación de los países que adopta el modelo, es la fuerte dependencia de la entrada de capitales para 
alimentar el ciclo ascendente. Las condiciones analizadas dejan en claro que el modelo se sostiene en base al endeudamiento externo. Por un lado, las condiciones competitivas impulsan las importaciones y bloquean las exportaciones, de manera que las expansiones suelen producir déficit comercial financiado con deuda. Por otro lado, las condiciones de valorización financiera impulsan el ingreso de capitales externos, muchas veces a partir del endeudamiento de actores locales. La combinación de déficit comercial, servicios de la deuda externa y la sistemática repatriación de ganancias de los inversores externos o la fuga de capitales de los actores locales abre paso a crecientes déficit de cuenta corriente, también financiados por deuda, que se enhebran en forma de círculo vicioso (véase gráfica 2).

Gráfica 2. Saldo de la cuenta corriente (en \% del PIB)

Argentina, 1976-1984

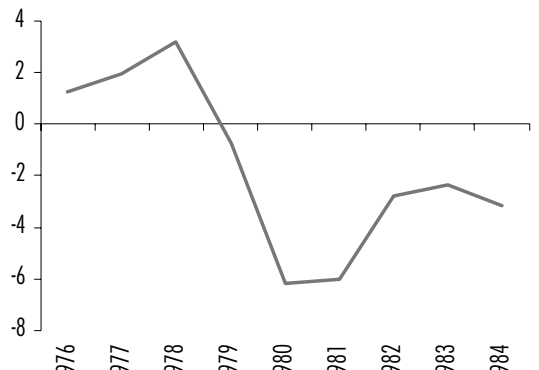

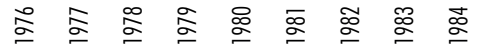

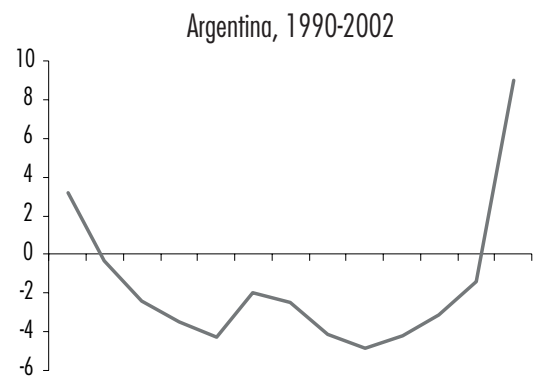

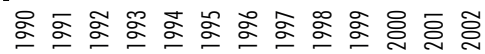

Argentina, 2014-2017

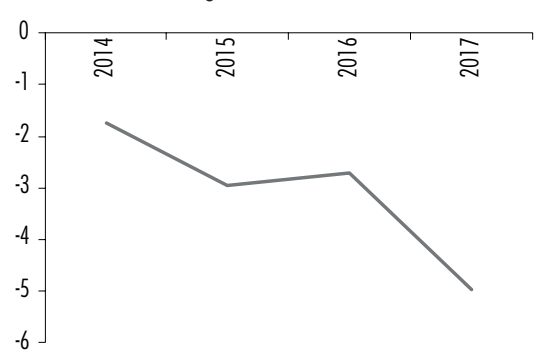

Portugal, 1991-2017

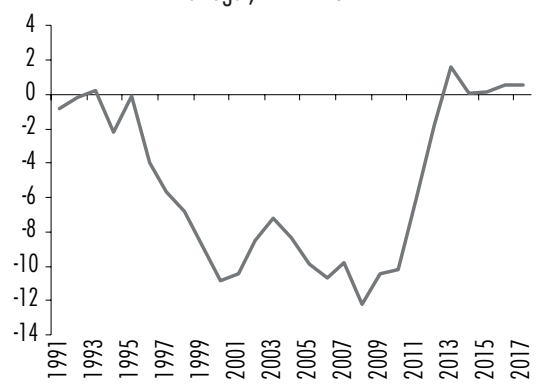

Fuente: elaboración propia con datos del Banco Mundial (<https://databank.worldbank.org/source/world-developmentindicators>). 
La centralidad de la deuda también marca el pulso de la duración de la fase expansiva del ciclo: mientras sea posible endeudarse, el modelo estará en condiciones de reproducirse a escala ampliada. Cuando por restricciones externas, por saturación interna o por la suma de desequilibrios, se restringe la capacidad de endeudarse, la fase del agotamiento y la crisis se torna inevitable. Es el caso de Argentina posterior a 1980, a 1998 y en la actualidad. Es también el caso del Portugal posterior a la crisis internacional y regional de 2008 (véase gráfica 3).

Gráfica 3. Evolución de la deuda externa (en \% del PIB)
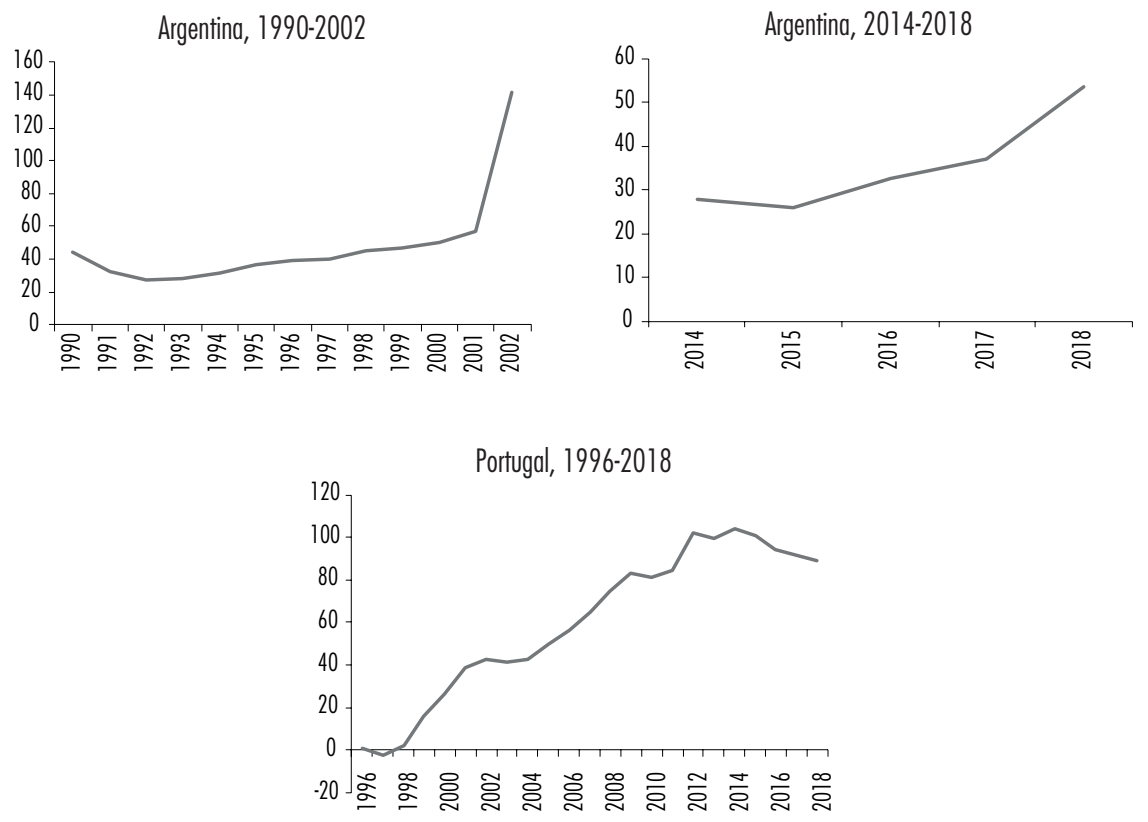

Fuente: elaboración propia con datos del Banco Mundial(<https://databank.worldbank.org/source/world-developmentindicators >).

Lo destacable en ambos casos es la dificultad que tienen para reaccionar frente a las fluctuaciones y a las crisis. Reis (2018, p. 90) destaca para Portugal una característica también constatable en Argentina: la adopción de los regímenes cambiarios mencionados impone una moneda determinada por las condiciones externas, lo cual conduce a una pérdida de control sobre el ciclo y sobre la capacidad de reacción frente a impactos externos o internos. Por eso, 
destaca el autor, la economía portuguesa (se agregaría el NPF en general) tiene como rasgo sobresaliente la inestabilidad.

En realidad, las dificultades para reaccionar tienen que ver con una pérdida de autonomía por la vía de la anulación de los instrumentos clásicos de política económica que es todavía más amplia. El "tríptico maldito" implica el abandono de múltiples instrumentos, como la política cambiaria, la política monetaria, la política arancelaria y paraarancelaria, introduciendo también restricciones severas en las políticas fiscales. La adhesión a diversos acuerdos regionales implica el abandono de buena parte de los instrumentos para ejecutar políticas activas (política industrial, compras gubernamentales, regulaciones al capital financiero y productivo extranjero). Un resultado de ello es la dificultad mayúscula para controlar el ciclo económico con políticas anticíclicas y reaccionar frente a desequilibrios graves. De igual forma, se limita al extremo las políticas de cambio estructural, con lo cual es muy difícil salir del cepo sin una transformación brutal de las políticas internas y de la inserción internacional. Pero es justo el grado de debilidad al que conduce el NPF es un blindaje relativamente eficiente contra ese tipo de giros (véase figura 1).

Figura 1. Neoliberalismo financiarizado en su etapa expansiva

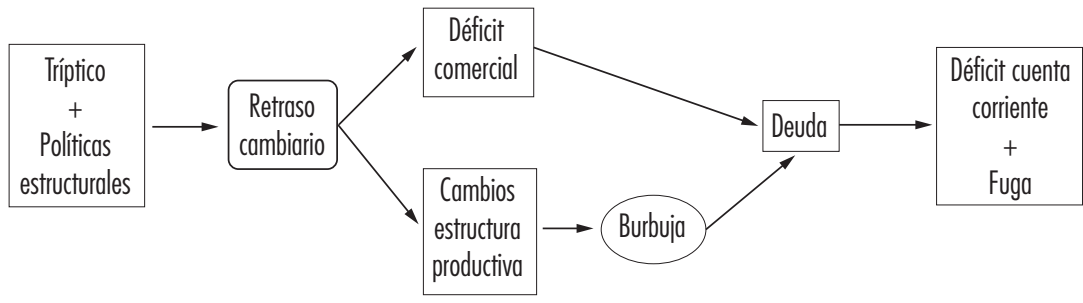

Fuente: elaboración propia.

\section{La crisis}

Si durante la etapa expansiva suele producirse un aflujo de capitales, con la crisis esa tendencia se invierte. Sin ese apoyo, el déficit comercial y de la cuenta corriente no puede sostenerse. Tampoco puede sostenerse la burbuja financiera e inmobiliaria. Su explosión inhibe el proceso de valorización especulativa y encadena una masiva salida de capitales. Pero dado que dicha salida también incluye las ganancias obtenidas, la fuga es mucho mayor que el ingreso e incluye la fuga de capitales locales, lo cual incrementa la intensidad de la crisis. 
Tanto para los países del sur europeo luego de la crisis de 2008, como para Argentina al inicio de las décadas de 1980 y del 2000, el sector privado tenía un alto endeudamiento que generaba una inestabilidad no sólo en el plano interno sino también en los acreedores. Por lo tanto, la solución -habitual en las crisis del NPF- consistió en una "ronda final de créditos de rescate". Organismos internacionales y países acreedores concedieron créditos al Estado, encargado de organizar la salida "ordenada" de los grandes financistas y asumiendo buena parte de la deuda privada. Así, se estatiza paulatina la deuda, mientras se provee las divisas a los grandes grupos financieros locales y externos en fuga. En general (y sí ocurrió en los casos analizados), los mecanismos del rescate no están al alcance del pequeño deudor, del que ha obtenido un crédito para comprar su casa, para consumo o ha realizado pequeñas inversiones especulativas. Los rescates suelen ser absolutamente asimétricos y descargan desde el comienzo el ajuste sobre las familias y las pequeñas empresas.

Sobreviene entonces una crisis fiscal, pues el Estado queda ahogado por el servicio de la deuda, que obliga a renegociar los pasivos con base en un programa impuesto por quienes comandan las negociaciones de parte de los acreedores. Como ejemplo pueden tomarse los sucesivos programas del FMI para Argentina entre 1982 y 1991, entre 1998 y 2003 (Brenta, 2019) o el acuerdo de agosto de 2018. Para Portugal, el programa de ajuste de 2011 impuesto por la Troika compuesta por la Comisión Europea, el Banco Central Europeo y el FMI (European Commission, 2011; Rodrigues y Adao, 2015).

Más allá de algunos cambios en la concepción del pensamiento de los organismos internacionales y los aggiornamento periódico, los programas tienen un diagnóstico y un conjunto de características comunes: se enfrenta a economías con alta inflación atribuida a causas monetarias y fiscales, con alta deuda que denotaría una hipertrofia del Estado y con problemas de competitividad derivados de un exceso de derechos laborales y jubilatorios. A eso se le agrega el déficit comercial y en cuenta corriente, que denotaría un exceso de consumo (cf. Bohoslawsky y Raffer, 2017). Así, los programas imponen un fuerte recorte del gasto público, sobre todo en materia social y administrativa, reformas tributarias regresivas, recortes en salarios y jubilaciones, flexibilización laboral, privatización de empresas públicas y desregulación de mercados. El diagnóstico y las medidas suelen profundizar el perfil productivo deformado preexistente y sólo se atacan los epifenómenos con un largo ajuste, pues muchos de los problemas se agravan con dichas políticas. Los déficit en cuenta corriente son temporalmente revertidos, aunque la contrapartida es el subconsumo, contracara de la mayor pobreza y el desempleo. 
Lo destacable es que, tanto en la etapa expansiva como en la crisis, se produce una fuga estructural de riqueza, una característica intrínseca de las economías subdesarrolladas que se acentúa en el modelo neoliberal y todavía más en el NPF. Los mecanismos, sin embargo, cambian de una fase a la otra. Si los fenómenos vinculados al intercambio desigual permanecen a lo largo del tiempo, en la expansión el eje principal puede identificarse en diferentes partidas de la cuenta corriente, como los intereses de la deuda o la remisión de utilidades. En los periodos de crisis, en tanto, las filtraciones se recuestan en la cuenta capital, vía fuga de capitales, salida de inversiones incrementadas por las ganancias previas, pagos del capital de la deuda y pérdida de reservas. De una u otra forma se manifiesta una sangría de riqueza creada al interior y que, expulsada del circuito de reproducción ampliada local y del espacio nacional, bloquea el proceso de desarrollo interno de las fuerzas productivas.

\section{HURGANDO EN LAS DIFERENCIAS}

Si los procesos enmarcados en el NPF tienen una raíz y un conjunto de características comunes, hay también importantes matices locales que les imprimen diferencias en las formas de manifestación y afectan tanto a la financiarización como a las crisis. La comparación de Argentina y Portugal permite enfocar esa diferenciación, no menor para formular estrategias de salida y políticas alternativas, así como para retomar el sendero del desarrollo económico y social. Debido a la extensión de este trabajo, no se hará un análisis sistemático de las diferencias, sino que se abordarán algunos problemas relevantes.

Tres elementos fundamentales para la diferenciación deben buscarse en el régimen monetario, el patrón de inserción internacional (ambos asociados entre sí) y en la regulación del mercado de trabajo. En el régimen monetario, las diferencias resultan visibles. Argentina recurrió en sus tres experiencias a regímenes que intentaban anclar el tipo de cambio nominal. El primer intento fue el establecimiento de un ajuste cambiario pautado, con devaluaciones preanunciadas y decrecientes, una "tablita cambiaria" con un tipo de cambio fijo e inamovible como norte. La segunda experiencia fue una moneda convertible con un tipo de cambio fijado por ley y garantizando con reservas $100 \%$ del circulante. La tercera más blanda, pues se sostiene en un tipo de cambio variable con flotación sucia para contener presiones devaluatorias. En los tres casos, sin embargo, existen mecanismos para modificar o abandonar el sistema sin 
quebrar acuerdos internacionales. ${ }^{7}$ El caso portugués es, desde esa perspectiva, absolutamente diferente, pues introduce una moneda externa, emitida por un Banco Central regional que determina tipos de cambio, políticas monetarias y cambiarias, objetivos de la regulación monetaria y la cantidad de moneda de la que podrá disponer anualmente cada país.

Las diferencias tienen consecuencias prácticas como la fase expansiva del ciclo. En Argentina, coexisten un riesgo de devaluaciones no previstas (riesgo cambiario) y de cesación de pagos (riesgo país) de la creciente deuda externa. Esto produce un diferencial positivo de tasas de interés frente a las tasas de referencia. La tasa de interés interna es, así, una función positiva del endeudamiento y de la apreciación del tipo de cambio real. La financiarización resultante tiene como eje fundamental el mercado financiero directo por medio del carry trade: se toman créditos a tasa baja en el exterior (al que acceden en general sólo grandes conglomerados locales o grandes bancos extranjeros), se cambian las divisas a pesos, que se colocan en inversiones financieras a las altas y crecientes tasas de interés locales (que, además, internalizan la tasa de inflación interna). Los intentos de esterilizar la expansión monetaria por parte del gobierno elevan aún más las tasas y colocan al Estado en el lugar de pagador en última instancia. Se gesta así un círculo vicioso de especulación lisa y llana, cuya duración depende de factores imprevisibles y en parte subjetivos, como la confianza o la coyuntura financiera externa.

En el caso de Portugal, se recortan dos etapas diferentes, pero enmarcadas en una secuencia larga y no en un proceso de impacto como en las experiencias argentinas. Al iniciarse la primera experiencia de NPF, Portugal había atravesado ya una larga fase de apertura comercial y liberalización financiera paulatinas en el marco de la CEE. ${ }^{8}$ Además, a diferencia de Argentina, el proceso se acompañaba con una asistencia regional para programas de reconversión, construcción de infraestructura y amortiguación del impacto social. La inserción internacional de Portugal marcaba una diferencia clave desde el inicio. En ese marco diferente, Portugal atraviesa dos fases del régimen monetario. La primera sucede al Tratado de Maastricht, con un régimen que

7 Por eso, los defensores más radicales del modelo propusieron la dolarización. Muchas empresas extranjeras entendieron que el abandono de la convertibilidad en 2002 vulneraba el régimen de protección de inversiones y demandaron al país en el CIADI, resuelto en general de manera exitosa para ellas.

8 Existían por entonces debates sobre la conveniencia de imponer un programa simultáneo de apertura, liberalización y normas monetarias, o si estas debían realizarse en secuencia, como planteaban McKinnon y Mathieson (1981). En las discusiones se comparaba las experiencias de Argentina y España (García Ruiz, 1992). 
preserva el escudo, aunque va quitando grados de libertad a las políticas internas a medida que las pautas de convergencia se van haciendo más rígidas. La segunda fase, con el ingreso efectivo a la Eurozona, quita por completo la soberanía monetaria. Especialmente en la segunda etapa, la fijación de las tasas de interés de referencia no sólo quedan fuera del campo de acción del Estado portugués, sino incluso de la dinámica económica del espacio nacional. A diferencia del caso argentino, la ausencia de una moneda local elimina el riesgo cambiario, mientras que (en especial hasta la crisis de 2008) la suposición de que las instituciones regionales garantizaban la asistencia ante situaciones de crisis, eliminaba casi por completo el riesgo de default. Por lo tanto, las tasas de interés nominales no se diferenciaron significativamente del resto de la región (cf. Alexandre y Bação, 2014, pp. 86-87).

El negocio financiero, por ende, no se asoció a la especulación lisa y llana en títulos y valores, sino que adquirió un carácter más sutil. La inflación más alta con tasas de interés nominales similares al resto de la región reducía la tasa de interés real. Por esos motivos, se produjo una financiación mucho más nutrida que en Argentina del consumo privado, lo que significó un endeudamiento de las familias más elevado. Además, alimentó un auge inmobiliario en el que el crédito a la construcción y a la compra de viviendas jugaban un papel esencial, aunque apoyado en una política pública de viviendas de la que carecía Argentina ( $c f$. Rodrigues et al., 2016). Por eso, aunque las características centrales del modelo se repiten (especialmente el retraso cambiario y la remodelación de la estructura productiva), las formas de obtención de rentas financieras y los mecanismos de transmisión son específicos (véase cuadro 2).

En Portugal, el marco general más "amigable" facilitó la acumulación de desequilibrios mucho más profundos que en Argentina, pues la financiación resultaba más laxa. Así, mientras Argentina rara vez supera un déficit en cuenta corriente del 5\% del PIB, Portugal quebró la barrera del 10\%.

Lo que "mejora" el modelo portugués en el auge, agrava el desarrollo de la crisis. En principio, para ambos países la crisis del modelo se asocia a una crisis de la deuda, una fuga de capitales y un quiebre de las finanzas públicas. En ambos casos se negocian rápidamente acuerdos que facilitan el rescate del sistema financiero privado y la transferencia de deudas al Estado ( $c f$. Brenta, 2019; Rodrigues y Adao, 2015). Sin embargo, las diferencias se manifiestan tanto en la forma inmediata de la crisis como en las alternativas de mediano y largo plazo.

Para Portugal la salida de la crisis es de tendencia deflacionaria, pues no puede actuar sobre el régimen monetario y la adecuación del tipo de cambio debe realizarse directamente sobre las variables nominales, sin tocar el tipo 
Cuadro 2. Esquema de similitudes y diferencias

\begin{tabular}{llll}
\hline & Expansión & Crisis & Alternativas \\
\hline Similitudes & "Tríptico maldito" & Problemas de la cuenta corriente & Expansión masa salarial \\
& Retraso cambiario & Formas del ajuste & Evolución del empleo \\
& Deformación productiva & Redistribución regresiva del & Mayor autonomía de la política \\
& & económica \\
\hline \multirow{3}{*}{ Diferencias } & Estatización de la deuda & Inversión pública \\
& Deuda & Tasas de interés & Políitca cambiaria \\
& Mercado de trabajo & Gestión del tipo de cambio & Políitca comercial \\
& Campos de la valorización financiera & & Política presupuestaria \\
& & & Ajuste de precios \\
\hline
\end{tabular}

Fuente: elaboración propia.

de cambio. En Argentina, en cambio, la crisis suele adoptar la forma de una explosión cambiaria, con una rápida transformación de los precios relativos y un ajuste del tipo de cambio real. La posibilidad de abandonar el régimen cambiario y recuperar algunos instrumentos de la política monetaria y cambiaria le permite, por una parte, realizar los ajustes redistributivos sobre las variables reales sin involucrar las nominales; puede, por ejemplo, reducir el poder de compra de los salarios incluso aumentándolos nominalmente, absorbiendo en el plano político una parte de la conflictividad social que tal medida provoca. También le resulta posible una devaluación real de la moneda, alterando el esquema de precios relativos, saliendo de los parámetros del modelo y encarando una salida de la crisis con mayores (en cantidad y en diversidad) exportaciones. Puede, además, recuperar más instrumentos de política económica, aunque eso no garantice sin más la efectividad de su utilización. Esas alternativas le están vedadas a Portugal, a menos que quiebre los acuerdos con la Unión Europea.?

Los impactos sobre el mercado de trabajo también deben analizarse con algo de cuidado, pues allí influyen algunas características geográficas e históresto de los acuerdos regionales ( $c f$. Louçã y Ferreira do Amaral, 2014). Sin embargo, una salida que no abandone la libre movilidad de capitales resulta por lo menos compleja. Una comparación entre los grados de libertad para una salida en ambos tipos de regímenes cambiarios e internacionales en los casos de Argentina y Grecia (véase Musacchio, 2012). 
rico-culturales no despreciables. Portugal tiene una larga tradición de fuertes corrientes emigratorias. Por lo tanto, la expulsión de mano de obra del sistema impulsa también una reducción de la población y, por el contrario, en los momentos de expansión suele captar el retorno de una parte de los emigrados. Las tasas de desempleo son, por lo tanto, menos fluctuantes; mientras la cuenta corriente se beneficia de transferencias familiares desde el exterior. Todo ello permite moderar el impacto de las variaciones del empleo sobre la distribución del ingreso. En Argentina, con una menor propensión a emigrar, los impactos sobre el desempleo y la distribución son más marcados. Es ese un elemento distintivo singular de los mecanismos de regulación de ambos países que ejerce una gran influencia en la diferenciación.

\section{5. ¿CÓMO CONSTRUIR ALTERNATIVAS?}

La construcción de alternativas es un desafío común a ambos países, así como para los modelos de tipo NPF. En general, una política diferente debe combinar tres dimensiones: un cambio en los precios relativos que reposicione la (re)producción de la base material, contener el drenaje de recursos y evitar la sangría de excedentes y, por último, articular un programa de desarrollo que transforme estructuralmente la base productiva. El desafío debe entonces combinar un programa sólido desde lo técnico; sustentarse en una constelación social con el poder suficiente para imponer el cambio desde el plano político; y finalmente, lograr la construcción un discurso que sustente el proceso desde el plano narrativo. Se trata, en última instancia, de reconstruir al menos en forma parcial la autonomía, proceso que se cristaliza en la recuperación de instrumentos de política económica. Se trata, por supuesto de un desafío que implica un cambio sociopolítico y no sólo técnico.

Desde esa perspectiva, de nuevo las experiencias comparadas de Argentina (entre 2002 y 2015) y Portugal (desde 2015) resultan miradores interesantes. Ambas experiencias muestran que tanto el modelo como la inserción internacional admiten un margen de maniobra para avanzar en proyectos alternativos. También muestran que internamente existen, incluso en las clases dominantes, márgenes para construir una constelación social y política diferente, aunque sea de manera precaria.

Desde el campo técnico, ambas experiencias muestran que un punto de apoyo de mediano plazo es reconstruir las bases del crecimiento a partir de una política expansiva que se apoye en una distribución progresiva del ingreso y la recreación del rol de los estados (tanto en la gestación del marco macro- 
económico y social, como en la regulación y en la inducción por medio de la inversión pública). Las dos experiencias muestran que una clave es quebrar la dependencia de recurrir a nuevo endeudamiento, lo que implica sostener cierto equilibrio fiscal y en la cuenta corriente, lo que suele llamarse "los superávit gemelos". En ese marco, la menor institucionalización de la restricción monetaria y de la sujeción en la inserción internacional da a Argentina un margen de maniobra mucho más amplio, en particular sobre el control directo del drenaje de excedentes por medio de restricciones al libre flujo del capital financiero o del control a la inversión extranjera. Con una menor flexibilidad, Portugal ha podido aprovechar en tiempos recientes, no obstante, brechas abiertas en la UE para escaparse al modelo de políticas absolutamente ortodoxas.

La experiencia argentina muestra, sin embargo, que la falta de consistencia técnica en las políticas de largo plazo pueden fortalecer la recreación del bloque político que puja por un retorno al viejo modelo. Para Portugal, ese desafío resulta doblemente difícil, pues los objetivos de transformación de largo plazo sólo pueden plasmarse en el marco de una política diferente por parte de la UE o rompiendo con la Eurozona, un camino que tanto desde lo técnico como desde lo político puede resultar demasiado espinoso.

En ambos casos se puso de manifiesto rápidamente que es más sencillo retomar un proceso de crecimiento que articular una verdadera política de desarrollo, para la cual es preciso un diagnóstico adecuado de las falencias internas, un proceso de planificación explícito y una sustentabilidad política de las nuevas condiciones.

\section{BIBLIOGRAFÍA}

Alexandre, F. y Bação, P. (2014), "A história de uma economia desequilibrada", en F. Alexandre, F. Bação, P. Lains, M. Martins, M. Portela y M. Simões, (orgs.), A economia portuguesa na Uniāo Europeia: 1986-2010, Coimbra, Actual Editora.

Álvarez, I., Luengo, F. y Uxó, J. (2013), Fracturas y crisis en Europa, Buenos Aires, Eudeba.

Azpiazu, D. y Schorr, M. (2010), Hecho en Argentina. Industria y economía (1976-2005), Buenos Aires, Siglo XXI Editores.

Bazza, A., Lauxmann, C. y Fernández, V. (2018), "Variedades del capitalismo en América Latina: el caso argentino”, en V. Fernández y M. Ebenau 
(eds.), Variedades de capitalismo entre centro y periferia, Buenos Aires, Miño y Dávila.

Beaud, M. (1987), Le system national/mondial hiérarchisé. Une nouvelle lecture du capitalisme mondial, París, La Decouverte.

Becker, J. y Jäger, J. (2012), "Integration in crisis: a regulationist perspective on the interaction of european varieties of capitalism", Competition and Change, vol. 16, núm. 3, julio, DoI <https://doi.org/10.1179/102452941 2Z.00000000012>

Block, F. (1977), The origins of international economic disorder, Berkeley, uc.

Bohoslawsky, J. y Raffer, K. (eds.) (2017), Sovereign debt crises: what have we learned?, Cambridge, cup.

Bortz, P. y Kaltenbrunner, A. (2019), "La dimensión internacional de la financiarización en economías subdesarrolladas", en P. Chena y P. Biscay (eds.), El imperio de las finanzas. Deuda y desigualdad, Buenos Aires, Miño y Dávila.

Brenta, N. (2019), Historia de la deuda externa argentina, Buenos Aires, Capital Intelectual.

Coimbra, P. (2017), "Desvalotização interna e desequilíbrios macroeconómicos na zona euro", en Economía com todos, Lisboa, Relógio d'agua.

European Commission (2011), "The Economic Adjustment Programme for Portugal”, European Economy, Ocassional Papers No. 79, Bruselas.

Gambarotto, F. y Solari, S. (2015), "The peripheralization of southern european capitalism within the EMU", Review of International Political Economy, vol. 22, núm. 4, agosto, DOI <https://doi.org/10.1080/09692290.2014.9 $55518>$

García Ruiz, J. (1992), "Sector financiero y apertura económica: una perspectiva comparada entre la Argentina y España”, en Ciclos en la Historia, la Economía y la Sociedad, vol. 2, núm. 3, julio-diciembre, Buenos Aires, FIHES.

Huffschmid, J. (2008), "Nicht die Krise, der Finanzkapitalismus ist das Problem", en M. Candeias y R. Rilling (eds.), Neues vom Finanzkapitalismus und seinem Staat, Berlin, Dietz.

Lapavitsas, C. (2013), Profiting without producing, Londres, Verso.

Léonard, Y. (2016), Histoire du Portugal contemporain, París, Chandeigne.

Louçã, F. y Ferreira do Amaral, J. (2014), A solução. Novo Escudo. O que fazer no dia seguinte á saída de Portugal do Euro, Alfragide, Lua de papel. 
Marcó del Pont, M. y Todesca, C. (2019), "Límites al desarrollo nacional en un contexto global de financiarización", en P. Chena y P. Biscay (eds.), El imperio de las finanzas. Deuda y desigualdad, Buenos Aires, Miño y Dávila.

McKinnon, R. y Mathieson, D. (1981), How to manage a repressed economy?, Princeton, Princeton University.

Mistral, J. (1986), "Régime international et trajectoires nationales", en R. Boyer (ed.), Capitalismes fin de siècle, París, Presses Universitaires de France.

Musacchio, A. (2019a), "Die Formen des Neoliberalismus und die Entwicklungsproblematik", Zeitschrift Marxistische Erneuerung, núm. 118, junio, Francfort, Forum Marxistische Erneuerung e.V.

(2019b), "Formas del neoliberalismo y relaciones internacionales", Ciclos en la Historia, la Economía y la Sociedad, núm. 53, segundo semestre, Buenos Aires, FiHes. Disponible en <http://ojs.econ.uba.ar/index.php/revistaCICLOS/article/view/1612/2284>

(2018), "El desarrollo en tiempos de neoliberalismo", en Coyuntura y Desarrollo, núm. 385, diciembre, Buenos Aires, FidE.

(2013), "El ajuste: origen de la crisis europea", Problemas del Desarrollo. Revista Latinoamericana de Economía, vol. 44, núm. 173, México, UnamIIEC, abril-junio.

(2012), "Umstrukturierung der Verschuldung und Wachstumsbedingungen: Griechenland und Argentinien im Vergleich", en PROKLA, núm. 168, julio, Münster, Westfälisches Dampfboot.

Rapoport, M., Madrid, E., Musacchio, A. y Vicente, R. (2000), Historia económica, politica y social de Argentina, Buenos Aires, Macchi.

Reis, J. (2018), A economia portuguesa. Formas de economia politica numa periferia persistente (1960-2017), Coimbra, Almedina.

(2009), Ensaios de Economia Impura, Coimbra, Almedina.

Rodrigues, J., Santos, A. y Teles, N. (2016), A financeirização do capitalismo em Portugal, Lisboa, Actual.

Rodrigues, M. y Adao e Silva, P. (org.) (2015), Governar com a Troika: politicas públicas em tempo de austeridade, Coimbra, Almedina.

Van der Pijl, K. (2014), The discipline of western supremacy. Modes of foreign relations and political economy, vol. III, Londres, Pluto.

(2006), Global rivalries from the cold war to Iraq, Londres, Pluto.

Wolf, M. (2015), The shifts and the shocks, Londres, Penguin. 